\title{
NIACIN AND PANTOTHENIC ACID EXCRETIONS OF HUMANS FED A LOW-METHIONINE, PLANT-BASED DIET ${ }^{1,2}$
}

\author{
Mary L. Duke, ${ }^{3}$ Constance KIES, ${ }^{4}$ and Hazel M. Fox ${ }^{5}$ \\ Department of Food and Nutrition, University of Nebraska, \\ Lincoln, Nebraska 68583 \\ (Received April 25, 1977)
}

\begin{abstract}
Summary The addition of a vitamin to a diet of humans has been shown to increase the excretion of that vitamin. The effects of an increase of one vitamin on another have not been investigated. The objective of the current project was to compare the effects of two supplementation patterns on the niacin and pantothenic acid excretion values of humans consuming a peanut butter-based diet. Two groups each received one of two supplementation regimens. One group received niacin, a multivitamin, or no supplement. One group received methionine alone, pantothenic acid alone or methionine plus pantothenic acid. The addition of either vitamin resulted in increased excretion of that vitamin. Urinary niacin excretion of the group that received pantothenic acid and/or methionine was greater than that observed with a multi-vitamin or no supplement. Urinary pantothenic acid excretion was suppressed when niacin was a supplement. Urinary pantothenic acid excretion of the methionine supplement group was greater than the excretion of the groups which received either niacin or multi-vitamin supplements. These data suggest some possible dangers in indiscriminate supplementation of food products.
\end{abstract}

Pantothenic acid and niacin are both known to be essential to metabolic processes, as a part of NAD and NADP and acetyl Coenzyme A (1-10). While these two vitamins operate independently of one another, an indirect relationship

${ }^{1}$ Supported by funds from Nebraska Agricultural Research Station Project 91-007 and C.S.R.S. Project NE-95.

2 Published as Nebraska Agricultural Research Station Journal Series No. 5194.

${ }^{3} 135$ Village West Mobile Home Park, Highway 31 South, Montgomery, Alabama 36108.

${ }^{4}$ Address of author to whom all correspondence should be sent: Prof. Constance Kies, 316 Food and Nutrition Bldg., University of Nebraska, Lincoln, NE 68583.

${ }^{5}$ Regents professor and chairman, Department of Food and Nutrition, University of Nebraska, Lincoln, Nebraska 68583. 
between niacin and pantothenic acid can be observed biochemically (11). However, little information exists on the practical significance of a niacin-pantothenic acid interrelationship as it occurs against a background food.

An earlier study from this laboratory ${ }^{6}$ observed a three-way interrelationship between niacin, pantothenic acid and nitrogen balance. Supplemental pantothenic acid resulted in a depressed niacin excretion and an improved nitrogen balance. The addition of either niacin or pantothenic acid depressed excretion of the other vitamin.

Low-protein diets can be classified into either of two groups: those limited in the amino acid lysine and those limited in the amino acid methionine. Since the earlier study ${ }^{7}$ investigated pantothenic acid and niacin excretion against a lysine-limited background food (wheat), the current study investigated pantothenic acid and niacin excretion against a methionine-limited background food (peanut butter). The objective of the current study was to compare the effects of methionine and/or pantothenic acid supplementation or niacin/multi-vitamin supplementation to a peanut butter based diet on the excretion of niacin and pantothenic acid by normal human subjects.

\section{EXPERIMENTAL}

Two 18-day human bioassay studies were carried out simultaneously. Each study was composed of a two-day nitrogen depletion period, a four-day nitrogen adjustment period and three experimental periods of four days each. The experimental plans for Studies 1 and 2 are given in Tables 1 and 2, respectively.

In Study 1, methionine and pantothenic acid were the experimental variables. Subjects received plant-based diets supplemented with $0.5 \mathrm{~g}$ methionine, $25.0 \mathrm{mg}$ pantothenic acid or $0.5 \mathrm{~g}$ methionine plus $25.0 \mathrm{mg}$ pantothenic acid. Nitrogen intake during the depletion period was $0.7 \mathrm{~g}$ nitrogen/subject/day, as shown in Table 1. During the adjustment and experimental periods, subjects received $4.7 \mathrm{~g}$ of nitrogen/subject/day.

In Study 2, niacin and a commercial multi-vitamin ${ }^{8}$ were the experimental variables, as shown in Table 2. Subjects received plant-based diets supplemented with $25 \mathrm{mg}$ niacin, 1 multi-vitamin or no supplement. Nitrogen intake during the depletion period was $0.7 \mathrm{~g}$ of nitrogen/subject/day. During the adjustment and experimental periods, subjects received $4.7 \mathrm{~g}$ of nitrogen/subject/day.

Experimental periods were randomly arranged in order to minimize the influence of the order of presentation. The menu pattern was the same for Studies 1 and 2 and in Tables 1 and 2. Supplements were consumed at the midday meal.

${ }^{6}$ Ünver, B. Niacin/pantothenic acid/protein interrelationships affecting the nutritive value of winter wheat for humans. Ph. D. Dissertation, University of Nebraska, Lincoln, Nebraska, 1974.

7 Ibid.

8 One-A-Day, Miles Laboratories, Elkhart, Indiana. 
Table 1. Methionine and/or pantothenic acid supplementation to a low-methionine, plant-based diet $^{\mathrm{a}}$.

\begin{tabular}{lccll}
\multicolumn{1}{c}{ Period $^{\mathrm{b}}$} & No. of Days & ${\text { Protein }(\mathrm{g} \mathrm{N} / \text { day })^{\mathrm{c}}}$ & \multicolumn{1}{c}{ Supplement } & Amount $^{\mathrm{d}}$ \\
\hline Depletion & 2 & 0.7 & none & \\
Adjustment & 4 & $4.7(\mathrm{M})$ & none & \\
Expt. 1 & 4 & $4.7(\mathrm{~PB})$ & L-Methionine & $0.5 \mathrm{~g}$ \\
Expt. 2 & 4 & $4.7(\mathrm{~PB})$ & Pantothenic acid & $25.0 \mathrm{mg}$ \\
Expt. 3 & 4 & $4.7(\mathrm{~PB})$ & L-Methionine + & $0.5 \mathrm{~g}+$ \\
& & & pantothenic acid & $25.0 \mathrm{mg}$ \\
\hline
\end{tabular}

a Diet pattern consisted of meals of the following: peanut butter $(90.7 \mathrm{~g})$, butteroil (varied), starch bread (one recipe), tomato juice $(100 \mathrm{~g})$ applesauce $(100 \mathrm{~g})$ peaches $(100 \mathrm{~g})$, pears $(100 \mathrm{~g})$, green beans $(100 \mathrm{~g})$, jelly or honey (varied), tea (limited to $1 \mathrm{tsp}$. dried instant/day) or coffee (limited to $3 \mathrm{tsp}$. instant dehydrated/day).

b Experimental periods 1-3 randomly arranged for subjects.

c $\mathbf{M}=$ Milk as a protein source.

$\mathrm{PB}=$ Peanut butter as protein source.

d The basal diet contributed an additional $4.38 \mathrm{mg}$ of pantothenic acid and $20.34 \mathrm{mg}$ of niacin per subject per day.

Table 2. Niacin-full vitamin supplementation to a low-methionine, plant-based diet ${ }^{\mathrm{a}}$.

\begin{tabular}{lccll}
\hline \multicolumn{1}{c}{ Period $^{\mathrm{b}}$} & No. of Days & ${\text { Protein }(\mathrm{g} \mathrm{N} / \text { day })^{\mathrm{c}}}$ & \multicolumn{1}{c}{ Supplement } & Amount $^{\mathrm{d}}$ \\
\hline Depletion & 2 & 0.7 & none & \\
Adjustment & 4 & $4.7(\mathrm{M})$ & none & \\
Expt. 1 & 4 & $4.7(\mathrm{~PB})$ & none & 1 tablet \\
Expt. 2 & 4 & $4.7(\mathrm{~PB})$ & Vitamin & $25 \mathrm{mg}$ \\
Expt. 3 & 4 & $4.7(\mathrm{~PB})$ & Niacin & \\
\hline
\end{tabular}

a Diet pattern consisted of meals of the following: peanut butter $(90.7 \mathrm{~g})$, butteroil (varied), starch bread (1 recipe), tomato juice $(100 \mathrm{~g})$, applesauce $(100 \mathrm{~g})$, peaches $(100 \mathrm{~g})$, pears $(100 \mathrm{~g})$, green beans $(100 \mathrm{~g})$, jelly or honey (varied), tea (limited to $1 \mathrm{tsp}$. dried instant/day) or coffee (limited to 3 tsp. instant dehydrated/day).

b Experimental periods 1-3 randomly arranged for subjects.

c $\mathrm{M}=$ Milk as a protein source.

$\mathrm{PB}=$ Peanut butter as protein source.

d Composition of multi-vitamin: Vit. A, 5,000 U.S.P. units; Vit. D, 400 U.S.P. units; thiamine, $1.5 \mathrm{mg}$; riboflavin, $1.7 \mathrm{mg}$; niacinamide, $20 \mathrm{mg}$; ascorbic acid, $60 \mathrm{mg}$; pyridoxine, $2 \mathrm{mg}$; folic acid, $0.1 \mathrm{mg}$; pantothenic acid, $10 \mathrm{mg}$; cyanocobalamin, $5 \mu \mathrm{g}$.

e The basal diet contributed an additional $4.38 \mathrm{mg}$ of pantothenic acid and $20.34 \mathrm{mg}$ of niacin per subject per day.

Subjects consumed a constant amount of coffee or tea each day throughout the study. Caloric intake was adjusted with soft drinks, hard candy, sucrose and jelly, honey or butteroil for subject weight maintenance. Sugar-free soft drinks and water were allowed ad libitum.

Subject data is included in Table 3. All subjects were normal, healthy young women who were students at the University of Nebraska and continued normal daily living patterns except for the collection of urine and feces and the eating of 
Table 3. Subject description ${ }^{\mathrm{a}}$.

\begin{tabular}{cccc}
\hline Subject number & Height $(\mathrm{cm})$ & Weight $^{\mathrm{b}}(\mathrm{kg})$ & Age (years) \\
\hline 1020 & 161.3 & 67.6 & 21 \\
1021 & 170 & 61.5 & 20 \\
1023 & 165 & 63 & 21 \\
1024 & 166 & 61.5 & 20 \\
1025 & 162 & 51.3 & 21 \\
1026 & 172.5 & 61.5 & 21 \\
1027 & 171 & 59 & 21 \\
1028 & 158.5 & 49.5 & 20 \\
1030 & 183 & 63 & 22 \\
1031 & 160 & 54.5 & 20 \\
1032 & 171 & 58 & 21 \\
1033 & 170 & 59 & 22 \\
1034 & 162.5 & 64 & 21 \\
1035 & 165 & 61.5 & 21 \\
1036 & 170 & 59 & 27 \\
1037 & 168.5 & 54 & 28 \\
\hline
\end{tabular}

${ }^{2}$ All subjects were female and White/American by Ethnic/Race Classification.

b Values at beginning of study.

meals at the diet laboratory. This project was reviewed and approved by the Committee on Human Investigation, University of Nebraska Medical Center.

Subjects were required to collect all urine and feces. Urine was collected in 24-hr lots and preserved under toluene. The 24- $\mathrm{hr}$ urine collections for the final three days of each 4-day experimental period were composited and frozen until analysis. Niacin and pantothenic acid were measured by microbiological assay (12) using Lactobacillus plantarum ATCC 8014 as the test microorganism. Daily creatinine determinations were done on $24-\mathrm{hr}$ urine samples to assure completeness of collections (13). Urinary and fecal nitrogen were determined by the boric acid modification of the Kjeldahl method (14) for another part of this project.

Resulting data were subjected to statistical analysis, including analysis of variance and Student-Neumann-Keuls tests. These computations were done by the Statistical Laboratory of the Agricultural Experiment Station, University of Nebraska, Lincoln.

\section{RESULTS AND DISCUSSION}

Individual urinary niacin excretions and urinary pantothenic acid excretions for Studies 1 and 2 are shown in Tables 4 and 5, respectively. A comparison of urinary niacin, pantothenic acid excretion and nitrogen balance is given in Table 6 . Details on nitrogen balance data were given in an earlier paper. ${ }^{9}$

${ }^{9}$ KIES, C. and H. M. Fox. Vitamin/amino acid/protein interrelationships influencing the protein value of peanut butter for humans. Presented at the Xth International Congress of Nutrition, Kyoto, Japan, 1975. 
Table 4. Urinary niacin excretion levels of subjects as affected by supplementation.

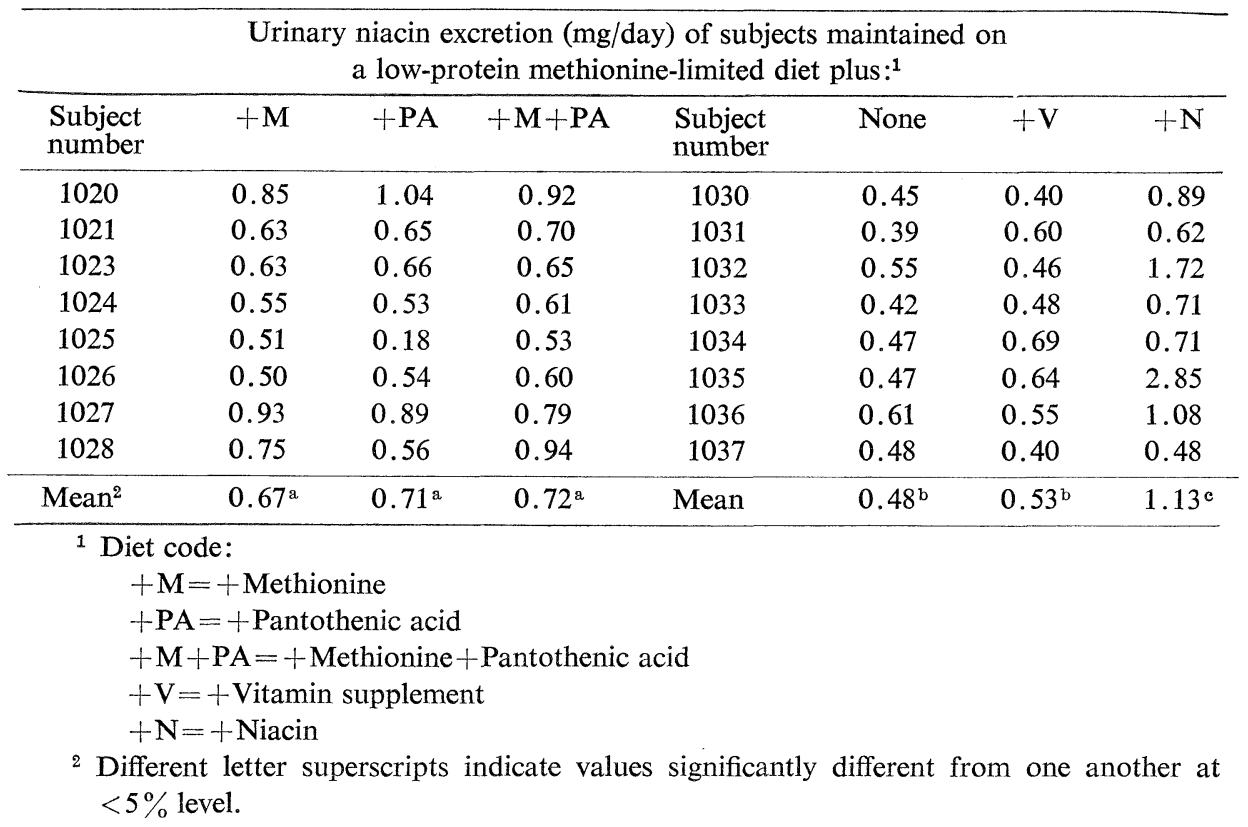

A statistically significant change in urinary niacin excretion was observed with the addition of a niacin supplement. No differences among the mean urinary niacin excretion values were observed when subjects received methionine and/or pantothenic acid. However, subjects receiving methionine and/or pantothenic acid had slightly higher mean urinary niacin excretions than those of subjects receiving no supplement or a multi-vitamin supplement. This could be a demonstration of an indirect relationship between Coenzyme A and NAD-NADP, which would ultimately involve pantothenic acid and niacin.

Two possibilities exist when increased vitamin excretion occurs. The obvious is that vitamin needs have been met and the excess is being excreted. The other possibility is that the vitamin is "rejected" because of the inability of the body to use that substance.

In view of the known indirect relationships between Coenzyme A and NADNADP (1-3), it is possible to assume that the increased excretion observed with pantothenic acid and/or methionine supplementation is an observation of an indirect relationship between pantothenic acid and niacin. Moreover, it can be assumed that body needs are being met.

Total mean urinary pantothenic acid losses, as shown in Table 5, show statistically significant differences between the means. Methionine and/or pantothenic acid supplementation significantly increased pantothenic acid excretion over that observed with a vitamin or a niacin supplement. Pantothenic acid excretion 
Table 5. Urinary pantothenic acid excretion of subjects as affected by supplementation.

\begin{tabular}{crrrrrrr}
\hline \multicolumn{7}{c}{ Urinary pantothenic acid excretion (mg/day) $)^{1}$ of subjects maintained } \\
on low-protein, methionine-limited diets plus : \\
\hline Subject No. & $+\mathrm{M}$ & $+\mathrm{PA}$ & $+\mathrm{M}+\mathrm{PA}$ & Subject No. & None & $+\mathrm{V}$ & $+\mathrm{N}$ \\
\hline 1020 & 3.36 & 8.02 & 12.88 & 1030 & 4.76 & 5.52 & 4.83 \\
1021 & 11.69 & 17.62 & 15.49 & 1031 & 5.23 & 9.47 & 3.92 \\
1023 & 12.86 & 14.67 & 17.24 & 1032 & 6.87 & 3.32 & 2.96 \\
1024 & 5.09 & 11.96 & 12.91 & 1033 & 3.22 & 3.63 & 4.72 \\
1025 & 7.53 & 12.03 & 16.48 & 1034 & 4.57 & 8.57 & 4.23 \\
1026 & 14.79 & 22.10 & 20.75 & 1035 & 3.33 & 5.72 & 5.57 \\
1027 & 7.29 & 9.83 & 10.19 & 1036 & 6.57 & 8.53 & 4.52 \\
1028 & 4.58 & 7.43 & 9.49 & 1037 & 4.67 & 5.03 & 4.72 \\
\hline Mean $^{3}$ & $8.40^{\mathrm{a}}$ & $12.96^{\mathrm{b}}$ & $14.43^{\mathrm{b}}$ & Mean & $4.90^{\mathrm{c}}$ & $6.22^{\mathrm{d}}$ & $4.43^{\mathrm{c}}$ \\
\hline
\end{tabular}

${ }^{1}$ Urinary pantothenic acid excretion values have been corrected for changes due to time in study that supplements were given. This was done by calculating a "standard value" based on the mean excretion of pantothenic acid for all periods regardless of diet or time. Mean pantothenic acid excretion for all subjects during each of the three time periods was calculated. Pantothenic acid excretion was adjusted for each individual subject in each period according to the following formula:

$\frac{\text { uncorrected subject value }}{x}=\frac{\text { uncorrected mean value for period }}{\text { standard value }}$

$x=$ corrected subject value. The corrected subject values were then arranged according to diet treatment.

2 Diet code:

$$
\begin{aligned}
& +\mathrm{M}=+ \text { Methionine } \\
& +\mathrm{PA}=+ \text { Pantothenic acid } \\
& +\mathrm{M}+\mathrm{PA}=+ \text { Methionine }+ \text { Pantothenic acid } \\
& +\mathrm{V}=+ \text { Vitamin supplement } \\
& +\mathrm{N}=+ \text { Niacin }
\end{aligned}
$$

${ }^{3}$ Different letter superscripts indicate values significantly different from one another at $5 \%$ level or better.

was significantly greater when a multi-vitamin supplement was included, as compared to periods in which niacin or no supplement was given. This may be partially due to the effect of the pantothenic acid in the multi-vitamin supplement, but it may also reflect a more favorable total nutritional environment. These data also support the position of the U.S. Food and Drug Administration that increases in vitamin levels above minimum requirements in multi-vitamin supplements have no beneficial effect.

A factor (see footnote to Table 5) was used to correct differences in pantothenic acid excretion data due to previous supplementation. The need for use of a factor with the pantothenic acid excretion data gives evidence that pantothenic acid may be retained in appreciable amounts for periods of four days. Niacin excretion data did not show a carry over from one period to the next, and therefore were not corrected. 
Comparison of the current study and the results of Ünver ${ }^{10}$ reveal that while niacin excretion was seemingly suppressed by pantothenic acid supplementation in Ünver's study, no such effect was observed in the current work. However, the conditions under which niacin excretion was suppressed in Ünver's experiment were not the same as in the current study.

In Ünver's ${ }^{11}$ experiment, which was carried out with human subjects, a wheatbased diet was used. Comparison between a lysine-limited diet in Ünver's study and methionine-limited diet in the current work creates a different nutritional environment. Ünver's study was conducted on three levels of protein intake, while the current study used one level of protein intake. Observations from both studies on similar protein intake levels ( 4.7 and $4.5 \mathrm{~g}$ of nitrogen per day) were nearly alike. However, in Ünver's experiment niacin excretion was suppressed by pantothenic acid intake at the higher protein level ( $6.5 \mathrm{~g}$ nitrogen/day). There was no comparable data in the data from the current study.

Larger pantothenic acid excretion in the current study as a result of methionine supplementation could be due to a positive relationship between methionine and pantothenic acid. Evidence exists suggesting that methionine improves the condition of pantothenic acid deficient animals $(16,17)$, but there is no evidence on the effects of methionine on pantothenic acid excretion.

Mean nitrogen balance data shown in Table 6 indicates that niacin, "full" vitamin, methionine and pantothenic acid all have a positive influence on nitrogen balance; however, methionine pantothenic acid supplementation combination resulted in a negative effect.

Table 6. Comparison of mean nitrogen balances with mean urinary niacin and pantothenic acid excretions.

\begin{tabular}{cccc}
\hline Diet fed $^{1}$ & Urinary niacin & Urinary pantothenic acid & N Balance \\
\hline & $\mathrm{mg} / \mathrm{day}$ & $\mathrm{mg} / \mathrm{day}$ & $\mathrm{g} \mathrm{N}$ \\
$+\mathrm{M}$ & $0.67^{\mathrm{a} 2}$ & $8.40^{\mathrm{d}}$ & $-0.70^{\mathrm{h}}$ \\
+PA & $0.71^{\mathrm{a}}$ & $12.96^{\mathrm{e}}$ & $-0.69^{\mathrm{h}}$ \\
+M+PA & $0.72^{\mathrm{a}}$ & $14.43^{\mathrm{e}}$ & $-1.11^{\mathrm{i}}$ \\
None & $0.48^{\mathrm{b}}$ & $4.90^{\mathrm{f}}$ & $-0.97^{\mathrm{i}}$ \\
$+\mathrm{V}$ & $0.53^{\mathrm{b}}$ & $6.22^{\mathrm{g}}$ & $-0.63^{\mathrm{h}}$ \\
+N & $1.13^{\mathrm{c}}$ & $4.43^{\mathrm{f}}$ & $-0.69^{\mathrm{h}}$ \\
\hline
\end{tabular}

1 Diet code:

$+\mathrm{M}=+$ Methionine

$+\mathrm{PA}=+$ Pantothenic acid

$+\mathrm{M}+\mathrm{PA}=+$ Methionine + Pantothenic acid

$+\mathrm{V}=+$ Vitamin supplement

$+\mathrm{N}=+$ Niacin

${ }^{2}$ Different letter superscripts indicate mean values significantly different from one another at the $5 \%$ level or better.

10 Ünver, op. cit.

11 Ibid. 
In an earlier report of nitrogen balance data, KIES and Fox ${ }^{12}$ proposed that the more negative nitrogen balance that resulted from methionine plus pantothenic acid supplementation was due to methionine toxicity induced by pantothenic acid supplementation. This could be an explanation for the increased pantothenic acid excretion as a result of methionine supplementation, either alone or combination with pantothenic acid.

Examination of pantothenic acid excretions of subjects receiving niacin seemingly shows the effects of an indirect niacin-pantothenic acid relationship. Examination of the niacin excretions of subjects receiving pantothenic acid does not show such a clear-cut relationship. In comparison to periods in which subjects received pantothenic acid as a supplement, pantothenic acid excretions of subjects receiving niacin were suppressed. Increases in pantothenic acid resulted in a greater need for niacin, thus a lower excretion.

Pantothenic acid excretion as a result of multi-vitamin supplementation was significantly different from that observed with either niacin or no supplement. The expectation is that the difference between the excretions would not be so great. In this case, the effect of the addition of other vitamins may result in higher excretions of pantothenic acid.

It would seem that if the above is true, then niacin excretions of subjects receiving pantothenic acid would also be suppressed. However, this is not so clear from the data. One explanation for these differences may be the differences between the supplement groups themselves. The relationships between pantothenic acid and methionine and the multi-vitamin and niacin were not the same. Niacin was a part of the multi-vitamin, while pantothenic acid and methionine were linked by a common coenzyme, Coenzyme A. However, this still does not fully account for the differences observed.

The authors acknowledge the technical assistance of the following individuals: Susan Whitford, Donna Geschwender, Mary Rhodes, Susan Anthony and Deb Nemat-Gorgani. The authors also would like to thank the 16 women who were subjects for the project.

\section{REFERENCES}

1) Freedman, A. D., Rumsey, P., and GrafF, S. (1960): The metabolism of pyruvate in the TCA. II. Tissue characteristic metabolism of pyruvate. J. Biol. Chem., 235, 1864.

2) BREMER, J. (1966): Comparison of acyl carnitines and pyruvate as substrates for rat-liver mitochondria. Biochem. Biophys. Acta, 116, 1.

3) Rose, I. A., and O'Connell, E. L. (1967): Mechanism of aconitase action. I. The hydrogen transfer reaction. J. Biol. Chem., 242, 1870.

4) OсноA, S. (1948): Biosynthesis of tricarboxylic acids by carbon dioxide fixation. II. Enzymatic mechanisms. J. Biol. Chem., 174, 133.

5) OCHOA, S., and BishniaC, W. (1952): Carboxylation reactions and photosynthesis. Science, 115, 297.

${ }^{12}$ KIEs, C. and Fox, H. M., op. cit. 
6) Horecker, B. L., and Smyrniotis, P.Z. (1952): The fixation of carbon dioxide in 6phosphogluconic acid. J. Biol. Chem., 196, 135.

7) Shieve, W., Ackerman, W. W., Ravel, J. M., and Sutherland, J. E. (1947): Biosynthesis involving pantothenic acid. J. Am. Chem. Soc., 69, 2567.

8) Olson, R. E., and Kaplan, N. O. (1948): The effect of pantothenic deficiency upon the coenzyme A content and pyruvate utilization of rat and duck tissues. J. Biol. Chem., 175, 515.

9) Klein, H. P., and Lipmann, F. (1953): The relationship of coenzyme A to lipide synthesis. II. Experiments with yeast. J. Biol. Chem., 203, 95.

10) Pugh, E. L., and WakIL, S. J. (1965): Studies on the mechanism of fatty acid snythesis. XIV. The prosthetic group of acyl carrier protein and the mode of its attachment to the protein. J. Biol. Chem., 240, 4727.

11) LYNEN, F. (1967): The role of biotin-dependent carboxylation in biosynthetic reactions. Biochem. J., 102, 381.

12) Freed, M. (1966): Methods of Vitamin Assay, Interscience Press, New York, p. 169.

13) Folin, O. (1914): On the determination of creatinine and creatine in urine. J. Biol. Chem., 17, 469.

14) Scales, F. M., and Harrison, A. P. (1920): Boric acid modification of the Kjeldahl method for crop and soil analysis. J. Ind. Eng. Chem., 12, 350.

15) Dinning, J. S., Neatrour, R., and Day, P. L. (1954): Interrelationships of pantothenic acid and methionine in lymphocyte production by rats. J. Nutr., 53, 557.

16) Dinning, J. S., Neatrour, R., and Day, P. L. (1955): A biochemical basis for the interrelationship of pantothenic acid and methionine. J. Nutr., 56, 431.

17) TAO, H. G., and Fox, H. M. (1976): Protein-pantothenic acid interrelationships in growing rats. 